\title{
Electrochemical Synthesis of ZnO Nanoparticles and preparation of Pea Starch/ZnO composite for Active Food Packaging Application
}

\author{
Yongjun $\mathrm{Wu}^{1,2, *}$, Yan $\mathrm{Gu}^{1}$, Ling Tong ${ }^{1}$, Ronghua Chen ${ }^{1}$, Nina Xie $\mathrm{X}^{3}$ \\ ${ }^{1}$ Maanshan Teacher's College, Maanshan 243041, PR China \\ ${ }^{2}$ College of Chemistry and Materials Science, Anhui Key Laboratory of Functional Molecular Solids, \\ Anhui Normal University, Wuhu 241000, PR China \\ ${ }^{3}$ Maanshan Ninth Junior High School, Maanshan 243000, PR China \\ *E-mail: wyj@massz.edu.cn,wyjmassz@163.com
}

doi: $10.20964 / 2019.12 .38$

Received: 6 July 2019 / Accepted: 17 September 2019 / Published: 29 October 2019

\begin{abstract}
$\mathrm{ZnO}$ nanoparticles were synthesized using a facile electrochemical technique in large-scale production. Nanocomposite films designed based on pea starch (PS) incorporated with $\mathrm{ZnO}$ nanoparticles were successfully prepared and characterized. Biopolymer films with high UV absorption and enhanced resistance to sunlight were obtained by samples incorporated with $\mathrm{ZnO}$ nanoparticles in concentrations between 1 and $5 \mathrm{wt} \% .5 \% \mathrm{ZnO}$ content incorporated nanocomposite matrix was the least permeable to water vapor. The interplay between the $\mathrm{ZnO}$ and the polymer matrix structure may have contributed to the significant decrease in water solubility of the PS/ZnO nanocomposite. The PS/ZnO (5 wt\%) nanocomposite film has the best antimicrobial activity among the films tested. Cyclic voltammetry analysis of the samples indicated higher conductivity of the PS/ZnO nanocomposite which can result in the enhancement of the antibacterial properties of starch-based polymer through the electrostatic discharge between $\mathrm{ZnO}$ nanoparticles and bacteria. Biopolymer film incorporated with $\mathrm{ZnO}$ nanoparticles exhibited excellent antibacterial activity and has the potential to be used to properly preserve the packaged foods by employing it as an active food packaging material.
\end{abstract}

Keywords: $\mathrm{ZnO}$ nanoparticles powder; Electrochemical technique; $\mathrm{PS} / \mathrm{ZnO}$ biopolymer films; Antibacterial activity

\section{$\underline{\text { FULL TEXT }}$}

(C) 2019 The Authors. Published by ESG (www.electrochemsci.org). This article is an open access article distributed under the terms and conditions of the Creative Commons Attribution license (http://creativecommons.org/licenses/by/4.0/). 